\title{
REFERENCE
}

\section{The 2003 Interagency Program Review of the Government Agencies Technology Exchange in Manufacturing (GATE - M)}

Stieren, D. C.

U. S. DEPARTMENT OF COMMERCE Technology Administration National Institute of Standards and Technology

Gaithersburg, MD 20899

$$
\begin{aligned}
& Q C \\
& 100 \\
& 456 \\
& 47076 \\
& 2003
\end{aligned}
$$

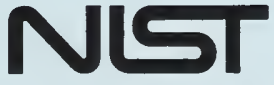

National Instifute of Standards and Technology

Technology Administration

U.S. Department of Commerce 


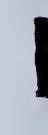

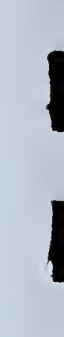

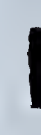




\section{The 2003 Interagency Program Review of the Government Agencies Technology Exchange in Manufacturing (GATE - M)}

Stieren, D. C.

U. S. DEPARTMENT OF COMMERCE Technology Administration National Institute of Standards and Technology

Gaithersburg, MD 20899

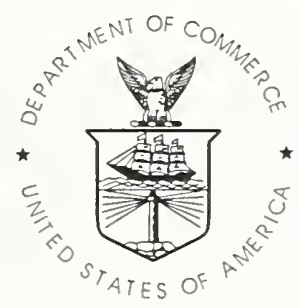

U.S. DEPARTMENT OF COMMERCE Donald L. Evans, Secretary

TECHNOLOGY ADMINISTRATION

Phillip J. Bond, Under Secretary for Technology

NATIONAL INSTITUTE OF STANDARDS

AND TECHNOLOGY

Arden L. Bement, Jr., Director 


\section{Foreword and Disclaimer}

This document describes the proceedings and results of the 2003 Interagency Program Review of the Government Agencies Technology Exchange in Manufacturing (GATEM). This review was held on June 24-25, 2003, at the National Institute of Standards and Technology (NIST) in Gaithersburg, Maryland.

GATE-M is a joint, interagency activity involving participation from six federal agencies. Representatives of the NIST Manufacturing Engineering Laboratory have served on the GATE-M Panel from 2001 to the present on behalf of the U.S. Department of Commerce, acting as both the Panel Chair and Panel Executive Secretary.

This document represents the views and perspectives of the NIST representatives to GATE-M. This publication was prepared by U.S. Government employees as part of their official duties and is, therefore, a work of the U.S. Government and not subject to copyright.

\section{Acknowledgements}

The author, who serves as the GATE-M Panel Executive Secretary, would like to recognize the following persons who serve as agency representatives to the GATE-M Panel. The contributions of these individuals to the progress and accomplishments of GATE-M and to the preparation of this document are both acknowledged and appreciated.

T. Daniel Cundiff, Office of the Secretary of Defense

Warren DeVries, National Science Foundation

Nanette Founds, National Nuclear Security Administration, U.S. Department of Energy

Charles Gaynor, National Nuclear Security Administration, U.S. Department of Energy

Dale Hall, National Institute of Standards and Technology ${ }^{2}$

George Hazelrigg, National Science Foundation

Julianne Levings, National Nuclear Security Administration, U.S. Department of Energy

John Vickers, National Aeronautics and Space Administration

Harvey Wong, U.S. Department of Energy

Walter Zimmer, Office of the Secretary of Defense

The author would also like to acknowledge the contributions of Elena Messina, Michael Postek, and John Slotwinski of NIST, as well as Richard Parisse of Tiburon Associates. These individuals served as facilitators and scribes during the working sessions of the GATE-M 2003 Interagency Program Review.

\footnotetext{
'Honeywell Federal Manufacturing employee on detail to the U.S. Department of Energy.

${ }^{2}$ Current Chair of the GATE-M Panel.
} 
Table of Contents

$\underline{\text { Page }}$

INTRODUCTION 1

GATE-M Background 1

PROGRAM REVIEW PROCEEDINGS 2

Intelligence in Manufacturing 3

Nano- / Micro-Scale Systems and Technologies $\quad 7$

PROGRAM REVIEW RESULTS 9

$\begin{array}{ll}\text { Intelligence in Manufacturing } & 10\end{array}$

Nano- / Micro-Scale Systems and Technologies 11

SUMMARY AND FUTURE DIRECTIONS 12

APPENDIX A: 2003 GATE-M Interagency Program Review Agenda 15

APPENDIX B: 2003 GATE-M Interagency Program Review Attendees 22 


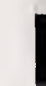




\section{INTRODUCTION}

This document describes the proceedings and results of the 2003 Interagency Program Review conducted by the Government Agencies Technology Exchange in Manufacturing (GATE-M). This review was held at the National Institute of Standards and Technology (NIST) on June 24-25, 2003.'

The purpose of the GATE-M 2003 Interagency Program Review was to provide a forum for the federal agencies participating or interested in GATE-M to exchange programlevel information about agency activities in the two areas that had been identified for joint address by GATE-M. These two areas are:

- Intelligence in Manufacturing, and

- Nano- / Micro-Scale Systems and Technologies.

These two areas were previously selected by the GATE-M Panel for this review due to their immediate importance and relevance to the participating agencies. ${ }^{2}$

The review set out to identify opportunities for collaboration, coordination, and leverage among the participating agencies in these areas, as well as agency priorities and the gaps in addressing them. The review also aimed at cultivating a greater understanding within the agencies about the manufacturing research and development (R\&D) programs occurring across the federal government. This review served as a vital step toward facilitating leveraged, coordinated, and even jointly planned and conducted efforts.

To set context for the description of the proceedings and results of the review, this report first provides background information about GATE-M.

\section{GATE-M Background}

GATE-M provides the voice of federal interests in U.S. manufacturing. GATE-M is unique in that it is the only current national-level effort that is focusing specifically and comprehensively on manufacturing $R \& D$ activities conducted at, or funded through, federal agencies.

GATE-M facilitates the exchange of information related to manufacturing $R \& D$ programs of its participating agencies, serving as a forum where opportunities for the coordination and leveraging of efforts can be identified and created. GATE-M is not a funded federal initiative, nor is GATE-M a policy mandate.

\footnotetext{
${ }^{1}$ Information on how to receive a comprehensive set of proceedings from the event, including presentation materials, can be obtained by contacting the author at david.stieren@nist.gov, or by visiting the GATE-M website, located at www.mel.nist.gov/gatem.

${ }^{2}$ Additional information about the process followed in the identification of these two issues can be found in NISTIR 6950, "Government Agencies Technology Exchange in Manufacturing (GATE-M)," which is available on the GATE-M website, located at www.mel.nist.gov/gatem.
} 
The following six federal agencies participate in GATE-M.

- The U.S. Department of Commerce (DOC), represented by the National Institute of Standards and Technology (NIST)

- The U.S. Department of Defense (DOD), represented by the Office of the Secretary of Defense, Acquisition, Technology, and Logistics

- The U.S. Department of Energy (DOE) Office of Energy Efficiency and Renewable Energy (EERE)

- The National Aeronautics and Space Administration (NASA), represented by the Marshall Space Flight Center (MSFC)

- The National Nuclear Security Administration (NNSA), a semi-autonomous branch of the U.S. Department of Energy

- The National Science Foundation (NSF), represented by the Directorate for Engineering

Each of the GATE-M agencies has a distinct and different mission, and each of these agencies includes manufacturing as a major element associated with the conduct of its mission. Each member agency of the GATE-M Panel has signed the GATE-M Charter as an indication of its commitment to GATE-M. The GATE-M Charter is an official vehicle recognizing the existence of GATE-M, while also providing the Panel members the authority to work with one another across the agencies in support of the GATE-M objectives. $^{3}$

The GATE-M effort was initiated to:

- allow the federal agencies with a manufacturing component in their mission to exchange and leverage information about their technical programs;

- coordinate manufacturing $R \& D$ programs among federal agencies to facilitate collaboration when it makes sense to leverage resources in the address of particular issues; and

- provide a forum for the agencies to advocate for issues on an interagency, national-level.

\section{PROGRAM REVIEW PROCEEDINGS}

The primary focus of the 2003 Interagency Program Review was the two initial technical areas that were identified by the GATE-M Panel for joint GATE-M address: Intelligence in Manufacturing and Nano- / Micro-Scale Systems and Technologies. These were identified as areas where all the participating GATE-M agencies had activity underway and felt they could benefit from new, coordinated activity. They were also identified as areas that all the agencies agreed they wanted to pursue further. It was this commonality

\footnotetext{
${ }^{3}$ The GATE-M Charter is available on the GATE-M webpage, www.mel.nist.gov/gatem.
} 
of interest and activity among the agencies that was the primary reason for their selection as the initial joint issues. ${ }^{4}$

Nearly 70 representatives of the six GATE-M agencies and selected other organizations participated in the two-day review, and over 35 presentations were provided. Most of the participants were program manager-level personnel who are involved in the daily operation of agency programs. The review presentations communicated information about the manufacturing programs and activities of each of the agencies in a broad sense, and they also provided detailed information about agency programmatic activities in the review's two technical focus areas.

After a series of presentations from each agency, facilitated working sessions were conducted for both technical areas to identify opportunities for collaboration, coordination, and leverage among the GATE-M agencies. The working sessions also targeted the identification of agency priorities and the gaps in addressing them.

Each working session was asked to:

- summarize the principal technical issues currently being addressed by each agency, including relevant knowledge about the focus of activity occurring within industry and academia;

- $\quad$ state the primary barriers to realizing widespread implementation;

- state the primary issues and barriers (technical or non-technical) not currently being addressed;

- summarize the opportunities for collaboration among the GATE-M agencies; and

- recommend a role for GATE-M, if appropriate.

The review agenda is included as Appendix A, and the list of review attendees is included as Appendix B.

The following sections further describe the scope of the review's two technical focus areas. The sections also define these descriptions by providing a listing of the ongoing programmatic activities and interests that each agency considered to be within the scope of the areas.

\section{Intelligence in Manufacturing}

As defined by the GATE-M Panel prior to the review, this area was intended to include all those technologies relevant to the development and incorporation of intelligent systems and controls into manufacturing operations. The review highlighted that the area of Intelligence in Manufacturing covers a broad spectrum of technical issues and is viewed quite differently by each of the GATE-M agencies.

\footnotetext{
${ }^{4}$ Also referenced earlier in this document, additional information about the process followed in the identification of these two issues can be found in the GATE-M NISTIR 6950 document available on the GATE-M website at www.mel.nist.gov/gatem.
} 
One way of defining an intelligent system is "a system that behaves appropriately in an uncertain environment, where appropriate behavior is that which maximizes the likelihood of success in achieving the system's goals." Within the context of GATE-M, Intelligence in Manufacturing represents an enabling, crosscutting technology area that has the potential to transform how manufacturing will be conducted in the future. All of the GATE-M agencies currently operate programs that directly address this area or are directly relevant in a broad sense.

When Intelligence in Manufacturing was chosen for joint address by GATE-M, the GATE-M Panel felt that significant opportunity existed for manufacturing R\&D to make a difference. For example, Panel members noted that work in this area could have a big potential impact on supply chain cost, quality, and reliability. Additionally, the manufacturing community is just beginning to tap the capabilities for manufacturing that are afforded by intelligent, open architecture control. The GATE-M Panel also felt strongly that there could be significant opportunities for agencies with product-oriented missions to apply technology developed elsewhere (i.e., at another GATE-M agency) to specific manufacturing problems associated with their product-specific domains.

The following topics were included among the presentations of the various agency programs in this area. These topics include issues where there is either current activity, or there is interest in future effort.

\section{- $\mathrm{DOC} / \mathrm{NIST}$}

- Intelligent systems and intelligent controls:

- measurement of system intelligence and learning, and metrics for intelligence

- system integration and interoperability in terms of open architecture control, STEP-NC (Standard for The Exchange of Product model Data - Numeric Control) conformance testing, metrology interoperability, and self-integrating systems

- standards, especially for part features and tolerances

- intelligent autonomous systems - ground vehicles, robots, and industrial autonomous vehicles

- secure systems in terms of cyber security of industrial control systems and critical infrastructure, validation, testing and evaluation methods and testbeds

- Smart machining:

- performance characterization

- machine tool errors and compensation, monitoring, and data

- machine tool self-diagnosis, self-calibration, and self-learning

- linking performance parameters to expected part tolerances

- virtual machining, including non-ideal machine performance

- STEP-NC

- process dynamics, models, and metrology

- high speed machining

\footnotetext{
5 "Intelligent Controls and Systems Integration at NIST/MEL," presentation by Albert J. Wavering, National. Institute of Standards and Technology (NIST), The 2003 Interagency Program Review of the Government Agencies Technology Exchange in Manufacturing, June 25, 2003, NIST, Gaithersburg, MD.
} 
- better material data and material properties for improved simulations, especially high-strain, high-temperature data

- material and machining knowledge integration

- smart sensor systems

- smart spindles

- in-situ part inspection strategies

- DOD

- Intelligent manufacturing and nanomanufacturing:

- new materials, coatings, processing knowledge and research

- intelligent processing of materials, including in-situ sensors, heuristic models and real-time controls

- non-destructive evaluation (NDE)

- nanomanufacturing, including modeling, nanoparticle manufacturing, nanoparticle processing, optimization, and sensors for nanoscale properties

- nanomaterials

- Supply chain networks as complex, adaptive systems:

- systems of agents

- prediction and control of complex adaptive system behavior for scheduling and control, simulation, information management, and design

- supply chain analysis and dynamics

- risk assessment and management

- DOE EERE

- Photovoltaic manufacturing:

- improved manufacturing processes

- cost reduction

- in-line diagnostics and intelligent processing (IDIP)

- large-scale module and component yield, durability, and reliability (YDR)

- Increased intelligence in manufacturing:

- sensors and automation

- model-based control

- sensor and controller performance monitoring

- plant-wide control and optimization

- inferential sensing

- Intelligent wireless technology:

- advanced wireless sensors

- interference rejection

- integrated intelligence

- reliable and secure networks

- power

- standards for communication

- interfaces and protocols

- smart sensors

- sensor agents

- dynamic hierarchy 


\section{- DOE NNSA}

- Seamless integration between design drawings and computer numeric control (CNC) machine tool control systems

- Virtual fabrication models and simulations

- Advanced quality acceptance technologies

- Improved efficiency and safety

- In-process gauging

- Flexible manufacturing

- Paperless procedures and quality documentation

- Real-time radiography inspection

- Feature-based applications for solid model-based product development

- Process design and analysis

- Enterprise modeling

- Model-based engineering and manufacturing

- Secure, wireless sensing

- NASA

- Interoperability and integrated design and manufacturing tools, to include a distributed, integrated engineering capability throughout the product lifecycle

- Cost analysis

- Virtual testing, qualification, and assembly

- Automated processing equipment and specialized cell automation

- Data management

- Design and analysis

- Rapid prototyping

- Materials and process information systems

- Manufacturing planning

- Collaborative engineering and interactive data management relating to materials, processes, and manufacturing functions

- Friction stir welding

- NSF

- Operations research

- stochastic networks and programming

- simulation and Monte Carlo analysis

- Service enterprise engineering

- transport and logistics

- financial engineering

- healthcare

- Manufacturing enterprise systems

- scalable enterprise systems

- supply chain design

- control and optimization

- systems for remanufacturing/product take-back

- production system issues in nanomanufacturing 
- Design, manufacturing, and product development

- environmentally benign semiconductor manufacturing, reconfigurable manufacturing systems, and advanced engineering of fibers and films (at Engineering Research Centers)

- machine tool systems, non-destructive evaluation, precision metrology, pharmaceutical processing, intelligent maintenance, plasma processing (at Industry / University Cooperative Research Centers)

- Manufacturing machines and equipment

- material removal and addition

- hybrid removal and addition

- sensing and control

- planning and optimization

- metrology

- machine design

- Theory of manufacturing

Although the review revealed that the agencies interpreted this area quite broadly, many opportunities for collaboration, leverage, and other future endeavors were identified. Additional information about these and other key findings and future GATE-M activities in this area, along with details about how the working groups responded to the previously stated tasks, are summarized later in this document.

\section{Nano- / Micro-Scale Systems and Technologies}

Nanotechnology has been defined to include research and technology development at the atomic, molecular or macromolecular levels, in the length scale of approximately $1 \mathrm{~nm}$ to $100 \mathrm{~nm}$ range, to provide a fundamental understanding of phenomena and materials at the nanoscale and to create and use structures, devices and systems that have novel properties and functions because of their small and/or intermediate size. ${ }^{6}$ Microtechnology generally includes systems and technologies relevant to microelectronics and microelectromechanical systems (MEMS).

When this area was chosen for joint address by GATE-M, the GATE-M Panel felt it represented an area that, although not highly mature, is fertile with good opportunities where manufacturing $R \& D$ could make a difference. This is a very important, emerging science and technology area that promises significant and broad impact to the future of U.S. manufacturing, as well as the U.S. economy and society on a large scale. This is an area with many manufacturing and systems issues. A number of electrical and mechanical application areas exist or are being investigated, as well as chemical and biological areas. Also, assembly areas and measuring techniques and tools could be promising topics to pursue.

Before the program review was conducted, the GATE-M Panel clearly articulated that the GATE-M focus in this area should be on manufacturing-related issues, capitalizing on

\footnotetext{
${ }^{6}$ Nanotechnology definition, Nanoscale Science, Engineering, and Technology Subcommittee of the National Science and Technology Council, February 2000, www.nano.gov.
} 
and complementing the investments in nano science and engineering being made as part of the National Nanotechnology Initiative (NNI). The NNI is a multi-agency federal initiative being overseen by the White House Office of Science and Technology Policy that supports long-term nanoscale R\&D leading to potential breakthroughs in a broad array of areas ${ }^{7}$.

Not surprisingly, the review highlighted that each of the agencies is very active in this technical area and that the work being pursued by each agency is germane to its particular mission. The following topics were included among the presentations of the various agency programs in this area. These topics include issues where there is either current activity, or there is interest in future effort.

\section{- DOC/NIST}

- Definition of standardized parameters and associated measurement and testing procedures to specify, describe, and verify the performance of key tools and processes for nanoscale manufacturing

- Establishment of traceability to a common standard as a key to achieving uniformity of results

- Definition of standardized architectures and models that support interoperability among manufacturing applications

- DOD

- Lack of DOD application targets by nanotechnology companies

- Cost of manufacturing as progression toward nanoelectronics evolves

- Integration and packaging methodologies for both microsystems and nanosystems

- Handling of materials

- Materials production and quality control

- Lack of manufacturing science to manufacture parts made of nanoparticles; consolidating large volumes of material

- Limited manufacturing capability for most nanotechnology applications, with few existing applications

- Need for a U.S. nanoscale manufacturing base

- DOE EERE

- Homogeneous dispersion of nanotubes, nanowires, and nanocatalysts in matrix

- Mass production methods for, and incorporation of nanotechnology into, micro chemical and thermal systems

- Bonding of tubes and wires with matrix

- DOE NNSA

- Need for funding of manufacturing technology in the area

- Need for a manufacturing infrastructure

- Need for nanometrology and standards

${ }^{7}$ Additional information about the National Nanotechnology Initiative can be found at www.nano.gov. 
- NASA

- Need for dependable, repeatable self assembly capabilities

- Integration/interoperability of nanodevices with micro- and macrodevices

- Need for coordination across the government and among the government, industry, and academia to tackle nanomanufacturing challenges

- NSF

- Manufacturing scale-up for industrial production

- Integration across dimensional scales (nano to macro)

- Net shape production to reduce material and energy waste

- Replacing the art and skill of manufacturing with knowledge and control

The review also revealed that GATE-M should have a valuable niche role to fill for the nation with respect to this technology area. Additional information about this and other key findings and future GATE-M activities in this area, along with details about how the working groups responded to the previously stated tasks, are summarized in the following sections of this document.

\section{PROGRAM REVIEW RESULTS}

In general, the program review clearly revealed that there are valuable roles to be played by GATE-M in each of the two technical areas covered. Review participants widely acknowledged that this event provided valuable information about the programmatic activities of each agency. In addition to providing a forum for the exchange of information about programs across the various other federal agencies, the review also served to communicate programmatic information within the various operating entities of the individual agencies.

By focusing on information exchange and the identification of opportunities for collaboration, GATE-M assists the agencies in fulfilling their missions and needs for U.S. manufacturing.

Recommendations related to Intelligence in Manufacturing and Nano- / Micro-Scale Systems and Technologies, as outcomes of the June 2003 GATE-M Review, are summarized in the following sections.

\section{Intelligence in Manufacturing}

The presentation of the agencies' program activities relating to this broad area resulted in several interesting items that were documented during the working sessions, then reported to the whole review audience at the end of the review.

Key findings and recommendations from the working sessions are highlighted below. 
- GATE-M should continue to serve as a visible and vocal "mouthpiece" for federal agencies in the area of manufacturing.

- GATE-M representation of an aggregated and unified perspective of federal needs could have a strong voice in the national dialogue regarding manufacturing.

- This could also serve to establish federal, if not national, priorities, and goals. To establish national priorities, other stakeholders of the manufacturing community including industry would need to be engaged.

- GATE-M has access mechanisms that can make possible the sharing of tools and technologies across federal agencies.

- This does not always occur today for a number of reasons, and GATE-M could serve as a good forum to make this happen.

- GATE-M could be a "one-stop source" for tool and technology sharing among the agencies.

- GATE-M could serve as a clearinghouse for manufacturing tools and facilities that can be shared, loaned, or surplused.

- On a broad scale across the government, this could serve to help optimize the use of valuable federal equipment and other resources.

- GATE-M could provide a forum to share best practices in the area across the agencies.

- This could include the creation of a subcommittee structure to address this and possibly other technical areas.

- GATE-M should consider conducting reviews such as this on an ongoing basis, perhaps annually.

- Much more information in this area exists within the agencies - only a portion was presented and discussed during this review.

- A lack of information about programs and activities in this area was cited as being a barrier to widespread implementation.

- Other organizations, including other federal agencies, state agencies, industrial consortia, and industrial trade and technical associations should also be engaged on specific subject matter as input to federal planning.

- The Internet should also be used to promote ongoing dialogue, perhaps with GATE-M providing an online discussion or meeting forum to develop the community in this area.

- A GATE-M role to simply serve as a facilitator for information exchange and expertise in the area would be very valuable.

Additionally, the following areas were identified as opportunities for collaboration in the area among the agencies:

- Systems interoperability

- Sensor-based control

- Model-based control

- Small-lot manufacturing

- Proliferation of STEP to manufacturing processes to include casting, forging, and welding 
- Common terminologies for such areas as modeling and simulation

- Development of the theory of manufacturing

\section{Nano- / Micro-Scale Systems and Technologies}

The presentation of the agencies' program activities relating to this area also resulted in several interesting items that were documented during the working sessions, then reported to the whole review audience at the end of the review.

Key findings and recommendations from the working sessions are highlighted below.

- Recognizing the need to coordinate GATE-M activities with those of the multiagency National Nanotechnology Initiative (NNI, previously mentioned in this report), GATE-M should serve as a consultative entity to the NNI for nanomanufacturing.

- This could be manifested by GATE-M either serving as a technical subcommittee or working/steering group of the NNI.

- GATE-M input should assist in the articulation of the NNI grand challenge for nanomanufacturing.

- GATE-M input should also target funding recommendations relating to nanomanufacturing.

- GATE-M should serve to catalyze the development of both short and long term roadmap goals for nanomanufacturing.

- GATE-M should plan and hold a national-level technical conference, perhaps on an annual basis, which would be focused on nanomanufacturing and that would bring together a broad audience of experts and stakeholders from the government, industry, and academia to discuss pressing issues and future national directions.

- GATE-M should provide an ongoing forum for collaboration and coordination among the agencies.

- This could include the development and operation of a mechanism to catalogue current funded projects and track future needs.

- The focus should be both technical and non-technical, and address business issues such as intellectual property.

- This should include both in-person and on-line meetings.

Additionally, the following items were highlighted as representing several of the most pressing issues being faced by the agencies:

- intellectual property barriers

- directed nanoassembly

- scaling of capabilities for eventual high-volume production and the fabrication of three-dimensional structures / moving from science to research to nanoproduction

- integration and packaging

- metrology and standards

- low cost mass production of microsystems 
- modeling

- durability and reliability of processes and products

- the need for a vision at the small scale

- the need for an infrastructure for pilot-scale prototyping

- the lack of cost and performance metrics

- the need for public education and public acceptance of nanotechnology

- the need for materials design tools for processing

- safety and health issues

- dependable delivery mechanisms

\section{SUMMARY AND FUTURE DIRECTIONS}

The GATE-M 2003 Interagency Program Review provided an effective forum for the exchange of information among the six GATE-M agencies in the areas of Intelligence in Manufacturing and Nano- / Micro-Scale Systems and Technologies. The review served to increase the level of understanding of the agency representatives of the portfolio of federal activities in each of these areas, both in terms of the programs from the other GATE-M agencies, as well as the programs of other operating entities within the individual agencies.

As a result of the review, a number of actions will be occurring over the next several months. These actions will involve the GATE-M Panel in aggregate in one sense, and in another sense, they will involve various representatives of the GATE-M agencies without significant input from the GATE-M Panel. To elaborate, the GATE-M Panel members will be moving forward, both collectively as a Panel and as advocates within their various agencies, to implement recommendations produced during the review. These recommendations will basically entail participation from the GATE-M Panel principals that will, at a high level, press forward the evolution of GATE-M as a national resource. There will also be actions that will not necessarily involve the GATE-M Panel as a whole, but will instead involve individual program personnel from the various agencies pursuing point-to-point collaborations with agencies or leveraging where it makes sense to do so. In these instances, the various GATE-M Panel principals will serve in a facilitating capacity to assist in the connection of technical personnel, as well as to assist in the development of mechanisms to enable collaborative and leveraged activities.

Both of these types of actions are worthwhile because collaboration, coordination, and leveraging of activities in these areas do not have to involve all six GATE-M agencies to be beneficial. There will be many instances during the evolution of GATE-M where it simply does not make sense for all the GATE-M agencies to be involved in a joint activity. All of the collaborations and leveraging that results from the review, however, should contribute to the realization that GATE-M has great potential to demonstrate benefits to federal agencies, to the manufacturing sector of the economy, and to the Nation in general. 
Table 1 below summarizes the near-term future directions of GATE-M in terms of actions associated with the two technical areas.

Table 1. Actions Relating to the Interagency Program Review Technical Areas

\begin{tabular}{|c|c|c|}
\hline Area & Action & Notes \\
\hline $\begin{array}{l}\text { Intelligence in } \\
\text { Manufacturing }\end{array}$ & $\begin{array}{l}\text { Develop an on-line web forum for } \\
\text { the exchange of information and } \\
\text { best practices relating to this area } \\
\text { to help develop the community. }\end{array}$ & $\begin{array}{l}\text { To be included on the GATE-M } \\
\text { webpage. }\end{array}$ \\
\hline $\begin{array}{l}\text { Intelligence in } \\
\text { Manufacturing }\end{array}$ & $\begin{array}{l}\text { Facilitate point-to-point } \\
\text { communications between agencies } \\
\text { in specific technical areas to } \\
\text { produce collaborations and } \\
\text { beneficial leveraging. }\end{array}$ & $\begin{array}{l}\text { GATE-M Panel facilitate and } \\
\text { advocate for this on behalf of } \\
\text { agencies as appropriate; } \\
\text { implementation responsibility } \\
\text { rests with agency program } \\
\text { manager / technical personnel. }\end{array}$ \\
\hline $\begin{array}{l}\text { Intelligence in } \\
\text { Manufacturing }\end{array}$ & $\begin{array}{l}\text { Consider other mechanisms to } \\
\text { promote ongoing, recurring } \\
\text { collaboration and cross-agency } \\
\text { input in this area. }\end{array}$ & $\begin{array}{l}\text { Mechanisms could include } \\
\text { creation of technical } \\
\text { subcommittees within GATE-M, } \\
\text { as well as focused technical } \\
\text { workshops. }\end{array}$ \\
\hline $\begin{array}{l}\text { Nano- / Micro-Scale } \\
\text { Systems and } \\
\text { Technologies }\end{array}$ & $\begin{array}{l}\text { Propose to the National } \\
\text { Nanotechnology Initiative (NNI) } \\
\text { that GATE-M serve the NNI in a } \\
\text { consultative manner in the area of } \\
\text { nanomanufacturing }\end{array}$ & $\begin{array}{l}\text { To be coordinated with the } \\
\text { National Nanotechnology } \\
\text { Coordination Office. }\end{array}$ \\
\hline $\begin{array}{l}\text { Nano- / Micro-Scale } \\
\text { Systems and } \\
\text { Technologies }\end{array}$ & $\begin{array}{l}\text { Facilitate point-to-point } \\
\text { communications between agencies } \\
\text { in specific technical areas to } \\
\text { produce collaborations and } \\
\text { beneficial leveraging. }\end{array}$ & $\begin{array}{l}\text { GATE-M Panel facilitate and } \\
\text { advocate for this on behalf of } \\
\text { agencies as appropriate; } \\
\text { implementation responsibility } \\
\text { rests with agency program } \\
\text { manager / technical personnel. }\end{array}$ \\
\hline $\begin{array}{l}\text { Nano- / Micro-Scale } \\
\text { Systems and } \\
\text { Technologies }\end{array}$ & $\begin{array}{l}\text { Consider other mechanisms to } \\
\text { promote ongoing, recurring } \\
\text { collaboration and cross-agency } \\
\text { input in this area. }\end{array}$ & $\begin{array}{l}\text { Mechanisms could include } \\
\text { focused technical workshops or a } \\
\text { national nanomanufacturing } \\
\text { conference. }\end{array}$ \\
\hline
\end{tabular}

Additionally, Table 2 summarizes the near-term future directions of GATE-M in terms of the continued evolution of GATE-M as a coordinating entity for the federal interests in manufacturing R\&D. The entries in the table below are both direct results of the 2003 Interagency Program Review, and they are issues that have been recognized by the GATE-M Panel as being critical to the continued development of GATE-M and that need to be addressed to help ensure success. 


\section{Table 2. Actions Relating to the Continued Evolution of GATE-M}

\begin{tabular}{|l|l|l|}
\hline \multicolumn{1}{|c|}{ Area } & \multicolumn{1}{c|}{ Action } & \multicolumn{1}{c|}{ Notes } \\
\hline GATE-M Awareness & $\begin{array}{l}\text { Continue to communicate about } \\
\text { the activities of GATE-M within } \\
\text { the GATE-M agencies, to other } \\
\text { federal agencies, and to industry } \\
\text { and university as appropriate }\end{array}$ & $\begin{array}{l}\text { Venues of opportunity include } \\
\text { conferences, seminars, } \\
\text { workshops, and other meetings } \\
\text { that are relevant to the federal } \\
\text { interests in manufacturing }\end{array}$ \\
\hline $\begin{array}{l}\text { Raising the Visibility } \\
\text { of Manufacturing in } \\
\text { the U.S. }\end{array}$ & $\begin{array}{l}\text { GATE-M agencies consider } \\
\text { jointly sponsoring a national-level } \\
\text { manufacturing forum to bring } \\
\text { together government policy } \\
\text { makers, members of the } \\
\text { manufacturing community, and } \\
\text { representatives of the labor force } \\
\text { to review, consider, and discuss } \\
\text { the current state of manufacturing } \\
\text { in the United States and the } \\
\text { challenges of the coming years. }\end{array}$ & $\begin{array}{l}\text { The conduct of the forum would } \\
\text { be targeted for 2005, and the } \\
\text { model for the event would be the } \\
\text { New Directions in Manufacturing } \\
\text { Forum sponsored by NIST in } \\
\text { 2003. }\end{array}$ \\
\hline $\begin{array}{l}\text { Re-Examine and } \\
\text { Consider New Joint } \\
\text { Issues for GATE-M to } \\
\text { Address }\end{array}$ & $\begin{array}{l}\text { Review the list of manufacturing } \\
\text { priorities previously submitted by } \\
\text { the GATE-M agencies to identify } \\
\text { which issues merit potential joint } \\
\text { address by GATE-M in 2004; } \\
\text { consider whether re-submission of } \\
\text { new priorities is appropriate. }\end{array}$ & $\begin{array}{l}\text { The process followed by the } \\
\text { GATE-M Panel in the submission } \\
\text { of agency issues, along with an } \\
\text { issue list, can be found in the } \\
\text { 2003 GATE-M report produced } \\
\text { by NIST. }\end{array}$ \\
\hline
\end{tabular}

8 "New Directions in Manufacturing," was conducted by the National Academies in Washington, D.C., in March 2003, with sponsorship from the NIST Manufacturing Engineering Laboratory. Additional information about the Forum can be found at www.nationalacademies.org/2003manufacturingforum 9 "The Government Agencies Technology Exchange in Manufacturing," NISTIR 6950, available on the GATE-M website at www.mel.nist.gov/gatem 


\title{
APPENDIX A: 2003 GATE-M Interagency Program Review Agenda
}

\author{
Government Agencies \\ Technology Exchange in Manufacturing \\ (GATE-M)
}

\section{INTERAGENCY PROGRAM REVIEW}

\author{
at the National Institute of Standards and Technology (NIST) \\ Gaithersburg, Maryland
}

June 24-25, 2003

\begin{abstract}
PURPOSE OF THIS REVIEW: To provide a forum for the federal agencies participating or interested in GATE-M to exchange program-level information about agency activities in the areas of Intelligence in Manufacturing and Nano- / Micro-Scale Systems and Technologies.
\end{abstract}

The review will result in the identification of opportunities for collaboration, coordination, and leverage among the agencies in these areas, as well as the identification of agency priorities and gaps in addressing them.

\section{Tuesdav, June 24}

Administration Building 101, Lecture Room B

8:00 Coffee / breakfast

8:30 Workshop Welcome

Dr. Karen Brown, Deputy Director, NIST

8:50 GATE-M Overview and Charge to the Participants

David Stieren, Strategic Relations Manager, NIST Manufacturing

Engineering Laboratory (MEL) and GATE-M Panel Executive

Secretary 
9:10 Department of Commerce / NIST

Dr. Dale Hall, Director, NIST MEL, and GATE-M Panel Chair

9:30 Department of Defense (DOD)

Dan Cundiff, Associate Director, Manufacturing Technology and

Affordability, Office of the Undersecretary of Defense for

Advanced Systems and Concepts

9:50 Department of Energy (DOE) National Nuclear Security Administration (NNSA)

Julianne Levings, Program Manager, Advanced Design and Production

Technologies Campaign

10:10 BREAK

10:30 Resume Agency Overviews

10:30 DOE Office of Energy Efficiency and Renewable Energy (EERE)

Harvey Wong, Special Assistant, EERE Industrial Technologies Program

10:50 National Aeronautics and Space Administration (NASA)

John Vickers, Manager, National Center for Advanced

Manufacturing, NASA Marshall Space Flight Center

11:10 National Science Foundation (NSF)

Dr. George Hazelrigg, Program Director, NSF Division of Design, Manufacture and Industrial Innovation

11:30 Preview of Afternoon Sessions

11:40 LUNCH 
Session I: Intelligence in Manufacturing

$12: 45-2: 00$ NSF Programs

- Dr. George Hazelrigg, Program Director for Manufacturing Machines and Equipment

- Dr. Jan Twomey, Program Director for Manufacturing Enterprise Systems

- Dr. Ronald Rardin, Program Director for Service Enterprise Engineering and Operations Research

- Dr. Tapan Mukherjee, Program Director for Engineering Research Centers

2:05-3:20

NASA Programs

- Integrated Intelligent Manufacturing at NASA

John Vickers for Majid Babai, NASA Marshall Space Flight Center

$3: 25-4: 40$

DOE NNSA Programs

- High Explosives Manufacturing

Will Bivens, BWTX-Pantex, Amarillo Plant

- Science-Based Manufacturing/ FB Mach

Danny Lewis, Honeywell Kansas City Plant

- Intelligent Manufacturing at the Y-12 National Security Complex Jim Snyder, BWTX Y-12 Plant

- Small Lot Manufacturing at Los Alamos National Laboratory

Brian Reardon, Los Alamos National Laboratory 
Session II: Nano- / Micro-Scale Systems and Technologies

$12: 45-2: 00$

NSF Programs

- Dr. Julie Chen, Program Director for Material Processing and Manufacturing (with acknowledgement to Dr. Haris Doumanidis, Program Director for Nanomanufacturing)

2:05-3:20

NASA Programs

- Nanotechnology: Current Status and Future Manufacturing Issues

Dr. James Arnold, NASA Ames Research Center (with acknowledgement to Dr. Meyya Meyyappan)

$3: 25-4: 40$

DOE NNSA Programs

- Nanostructured Materials at the Y-12 National Security Complex Hal Clift, BWTX-Y12 Plant

- Micro/Nano Technologies and Manufacturing at the Kansas City Plant Larry Zawicki, Honeywell Kansas City Plant

- Nanotechnology at Sandia Labs: Activities and Issues Greg Cardinale, Sandia National Laboratories

4:45 Day 1 Summary and Day 2 Preview

5:00 ADJOURN 
Wednesday, June 25

NIST Administration Building 101, Lecture Room B

$7: 30$

Coffee / breakfast

8:00

Agenda Review / Plan for the Day

8:15

Technical Review Sessions

Session III: Intelligence in Manufacturing

8:15-9:30

DOE EERE Programs

- DOE Photovoltaic Manufacturing R\&D Project

Richard L. Mitchell, Senior Project Coordinator II at the National Center

for Photovoltaics, National Renewable Energy Laboratory

- Increasing Intelligence In Manufacturing

Dr. Gideon Varga, Technology Manager for Sensors \& Automation, DOEEERE Industrial Technologies Program

- Intelligent Wireless Technology: Past, Present, and Future

Dr. Wayne W. Manges, Industrial Wireless Program, Oak Ridge

National Laboratory

9:35-10:50

DOD Programs

- DOD Manufacturing Technology Overview

Marty Ryan, Chair, Manufacturing Technology Advanced Manufacturing Enterprise Subpanel, Naval Air Systems Command

- Air Force Research Laboratory Intelligence Manufacturing \& NanoManufacturing

John Busbee, Team Lead, Manufacturing R\&D, Air Force Research Laboratory

- Supply Chain Issues - Intelligent Manufacturing

Jack White, The Altarum Institute 


\section{0:55-12:10 DOC / NIST Programs}

- Intelligent Systems and Intelligent Controls Albert Wavering, Acting Chief, NIST Intelligent Systems Division

- Smart Machining Kevin Jurrens, Acting Chief, NIST Manufacturing Metrology Division

\section{Session IV: Nano- / Micro-Scale Systems and Technologies}

$8: 15-9: 30$ DOE EERE Programs

- Industrial Materials for the Future Scott Richlen, Team Leader, DOE-EERE Industrial Technologies Program

- Nanotechnologies in the Chemicals Industry Dr. Brian Valentine, Technical Manager - Chemicals Program, DOE-EERE Industrial Technologies Program

- Micro Chemical And Thermal Systems Dr. Robert Wegeng, Chief Engineer, Pacific Northwest National Laboratory

- DOD Overview

Pete Black, Chair, DOD Manufacturing Technology Electronics Processing \& Fabrication Subpanel, U.S. Army Aviation \& Missile Systems Command

- Nanomanufacturing in the NNI: National and DOD Perspectives Dr. James Murday, Chief Scientist (Acting), Office of Naval Research and Executive Secretary, NNI

- Army Manufacturing Research, Development, and Education Center for Nanotechnology Mark Mezger, Nanotechnologies Program Coordinator, U.S. Army Tank Automotive \& Armaments Command 


\section{0:55-12:10 DOC / NIST Programs}

- Metrology and Manufacturing at the Nanoscale: Nanotechnology in MEL Kevin Lyons, Program Manager, NIST Integrated Nano-to-Millimeter Manufacturing Technologies Program

- Semiconductor Research at NIST

David Blackburn, Deputy Chief, NIST Semiconductor Electronics Division

\section{2:15 LUNCH}

1:00 GATE-M Issue Working Sessions

Group A: Intelligence in Manufacturing

Facilitator: Dr. John Slotwinski

NIST Manufacturing Engineering Laboratory

Scribe: $\quad$ Elena Messina

NIST Manufacturing Engineering Laboratory

\section{Group B: Nano- / Micro-Scale Systems and Technologies}

Facilitator: Dr. Richard Parisse

Scribe: $\quad$ Dr. Michael Postek

NIST Program Office

Working Group Reports 
APPENDIX B: 2003 GATE-M Interagency Program Review Attendees

Final Participants List

GATE-M

June 24-25, 2003

National Institute of Standards and Technology (NIST), Gaithersburg, MD

Glenn Allgood

Oak Ridge Nat'l.

$\mathrm{Lab} / \mathrm{DOE}$

James Arnold

UC Santa Cruz

NASA Ames Research

Ctr.

Amit Bagchi

NIST

Kristin Bennett

DOE

William Bivens

BWXT-Pantex

Peter Black

Army Aviation \&

Missile Command

Dave Blackburn

NIST

John Busbee

AFRL/MLMT

Gregory Cardinale

Sandia National Lab

Joseph Carpenter

U.S. Dept. of Energy

Julie Chen

Nat'l. Science

Foundation
J. Hal Clift

DOE/NNSA/Y-12 Nat'l.

Security

Perry Cowen

NNSA ADAPT

Dan Cundiff

OSD

Alkan Donmez

NIST

Nanette Founds

DOE-NNSA

Michael Frederickson

American

Competitiveness

Carol Gardinier

U.S. Army

Charlie Gaynor

NNSA, NA-12

Dana Granville

U.S. Army Research

$\mathrm{Lab}$

Esin Gulari

Nat'l. Science

Foundation

Dale Hall

NIST

Howard Harary

NIST
George Hazelrigg

Nat'l. Science

Foundation

Charles Hemmeline

U.S. Dept. of Energy

Rob Ivester

NIST

Kevin Jurrens

NIST

J. Bruce Kelley

Sandia National Labs

Sharon Kemmerer

NIST

Julianne Levings

DOE/NNSA/NA-123

Danny Lewis

Honeywell FM\&T

Kevin Lyons

NIST

Wayne Manges

Oak Ridge National Lab

Toni Marechaux

The National Academies

Elena Messina

NIST 
Mark Mezger

U.S. Army TACOM-

ARDEC

John Michaloski

NIST

John Mistretta

AFRL/MLM

Richard Mitchell

Nat'l. Renewable Energy

$\mathrm{Lab}$

Tapan Mukherjee

NSF

James Murday

Office of Naval

Research

Richard Parisse

Tiburon Associates, Inc.

Robert Polvani

NIST

Michael Postek

NIST

Ronald Rardin

NSF

Steven Ray

NIST

Brian Reardon

Los Alamos National

$\mathrm{Lab}$

Scott Richlen

U.S. Dept. of Energy

Martin Ryan

NAVAIR
John Slotwinski

NIST

Jim Snyder

BWXT Y-12 LLC

David Stieren

NIST

E. Clayton Teague

NNCO

Jan Twomey

NSF

Brian Valentine

U.S. Dept. of Energy

Gideon Varga

U.S. Dept. of Energy

John Vickers

NASA-MSFC

Anthony Vigliotti

American

Competitiveness

Theodore Vorburger

NIST

Albert Wavering

NIST

Robert Wegeng

Pacific NW Nat'l. Lab

Steven Weiner

Pacific NW Nat'l. Lab

James Whetstone

NIST

Jack White

Altarum
Harvey Wong

U.S. Dept of Energy -

EER

Larry Zawicki

Kansas City Plant

Walter Zimmer

OSD AS\&C OTT 


